\title{
Drosophila Neto is essential for clustering glutamate receptors at the neuromuscular junction
}

\author{
Young-Jun Kim, ${ }^{1}$ Hong Bao, ${ }^{2}$ Liana Bonanno, ${ }^{1}$ Bing Zhang, ${ }^{2}$ and Mihaela Serpe ${ }^{1,3}$ \\ ${ }^{1}$ Program in Cellular Regulation and Metabolism, National Institute of Child Health and Human Development, National \\ Institutes of Health, Bethesda, Maryland 20892, USA; ${ }^{2}$ Department of Zoology, University of Oklahoma, Norman, Oklahoma \\ 73019, USA
}

\begin{abstract}
Neurotransmitter receptor recruitment at postsynaptic specializations is key in synaptogenesis, since this step confers functionality to the nascent synapse. The Drosophila neuromuscular junction (NMJ) is a glutamatergic synapse, similar in composition and function to mammalian central synapses. Various mechanisms regulating the extent of postsynaptic ionotropic glutamate receptor (iGluR) clustering have been described, but none are known to be essential for the initial localization and clustering of iGluRs at postsynaptic densities (PSDs). We identified and characterized the Drosophila neto (neuropilin and tolloid-like) as an essential gene required for clustering of iGluRs at the NMJ. Neto colocalizes with the iGluRs at the PSDs in puncta juxtaposing the active zones. neto loss-of-function phenotypes parallel the loss-of-function defects described for iGluRs. The defects in neto mutants are effectively rescued by muscle-specific expression of neto transgenes. Neto clustering at the Drosophila NMJ coincides with and is dependent on iGluRs. Our studies reveal that Drosophila Neto is a novel, essential component of the iGluR complexes and is required for iGluR clustering, organization of PSDs, and synapse functionality.
\end{abstract}

[Keywords: glutamatergic synapses; postsynaptic density; glutamate receptor; synapse assembly; auxiliary subunits; Drosophila; neuromuscular junction]

Supplemental material is available for this article.

Received December 16, 2011; revised version accepted March 22, 2012.

Once neurons reach their correct postsynaptic targets, a cascade of events marks the beginning of synaptogenesis. The pre- and postsynaptic compartments are kept in register by adhesion molecules, while active zone precursor vesicles and synaptic vesicles arrive at the presynaptic specialization (Akins and Biederer 2006). The assembly of the presynaptic active zones appears to involve the delivery of prefabricated transport packets (Ahmari et al. 2000), although sequential arrival of components has been observed at specialized synapses (RegusLeidig et al. 2009). The postsynaptic assembly, however, seems to largely depend on gradual de novo clustering of component proteins (Bresler et al. 2004). The formation of the postsynaptic densities (PSDs) culminates with the recruitment of neurotransmitter receptors. Neuronal activity triggers further synthesis and aggregation of receptor complexes and synapse maturation, stabilization, and growth.

\footnotetext{
${ }^{3}$ Corresponding author.

E-mail serpemih@mail.nih.gov.

Article published online ahead of print. Article and publication date are online at http://www.genesdev.org/cgi/doi/10.1101/gad.185165.111.
}

In contrast to the rich understanding of nicotinic acetylcholine receptor (nAChR) clustering at the mammalian neuromuscular junction (NMJ), clustering of the ionotropic glutamate receptors (iGluRs) that form the majority of central synapses remains less understood. Considerable advances have been made toward identifying proteins that interact with the C-terminal tails of iGluRs and regulate their membrane trafficking, anchoring at the synapses, and involvement in intracellular signaling cascades (Shepherd and Huganir 2007). In the postsynaptic compartment, proteins that contribute to glutamate receptor clustering at the synapses include PDZ domain-containing proteins, cytoskeleton-binding and scaffolding components, and proteins that control endosomal trafficking (Kim and Sheng 2004; Groc and Choquet 2006). Receptor trafficking and assembly signals have also been found in the N-terminal domains of the iGluRs (Passafaro et al. 2003; Hansen et al. 2010; Kumar et al. 2011). Moreover, recent studies using reconstituted synapses have identified a number of presynaptic adhesion molecules and secreted factors that participate in receptor clustering through trans-synaptic protein interactions. For example, Narp (neuronal activity-regulated 
pentraxin) or other pentraxins secreted from the presynaptic neurons (NP1 and NRP) bind to the N-terminal domain of GluA4 and are critical trans-synaptic factors for GluA4 recruitment at the synapses (O'Brien et al. 1999; Sia et al. 2007). The direct coupling of the $\mathrm{N}$-terminal domain of GluA2 to $\mathrm{N}$-cadherin promotes enrichment of AMPA receptors at synapses and maturation of spines, although this interaction could occur in cis or in trans, since N-cadherin is present on both pre- and postsynaptic membranes (Saglietti et al. 2007). These trans-synaptic clustering strategies apply to subsets of iGluR subunits, and it is not clear whether they have a central role in the organization of postsynaptic domains in vivo or rather provide modulatory functions.

The Drosophila NMJ is a glutamatergic synapse similar in composition and function to the mammalian central AMPA/Kainate synapses. The fly NMJ iGluRs are heterotetrameric complexes composed of three essential subunits-IIC, IID, IIE-and either IIA or IIB (DiAntonio 2006). Type A and type B receptor complexes differ in their single-channel properties, synaptic responses and localization, and regulation by second messengers (DiAntonio 2006). Previous studies have shown that the nascent synapses are predominantly type A complexes and change their subunit compositions toward more B-type complexes upon maturation that relies at least in part on CaMKII activity (Morimoto et al. 2009).

How do iGluR complexes traffic to and cluster at the NMJ? In flies, none of the NMJ iGluR subunits have PDZbinding motifs. Live-imaging studies on growing synapses have shown that iGluRs from diffuse extrasynaptic pools stably integrate into immature PSDs, but Discs large (Dlg), the fly PSD-95 ortholog, and other postsynaptic proteins remain highly mobile (Rasse et al. 2005). Dlg does not colocalize with the iGluR receptors at the PSDs and instead is adjacent to the PSDs. Moreover, iGluRs are localized and clustered normally at the NMJ of $d l g$ mutants, although the type B receptor is reduced in levels (Chen and Featherstone 2005). The only protein shown to bind directly to iGluR subunits is Coracle, a homolog of mammalian brain 4.1 proteins. Coracle appears to stabilize type A but not type B receptors by anchoring them to the postsynaptic spectrin-actin cytoskeleton (Chen et al. 2005). Several more postsynaptic proteins have been identified that regulate the subunit compositions and the extent of iGluR synaptic localization, but no molecules other than the receptors themselves were shown to be absolutely required for clustering of the receptor complexes.

One possible link in understanding the trafficking and clustering of iGluRs at the fly NMJ could be provided by the emerging families of auxiliary subunits. Auxiliary subunits are transmembrane proteins that avidly and selectively bind to mature iGluRs and form stable complexes at the cell surface. They can modulate the functional characteristics of iGluRs and may also mediate surface trafficking and/or targeting to specific subcellular compartments (Jackson and Nicoll 2011). Auxiliary proteins described so far include stargazin and its relatives (Tomita et al. 2003; Milstein and Nicoll 2008), cornichon homolog-2 and homolog-3 (Schwenk et al. 2009), Cyste- ine-knot AMPAR-modulating protein (von Engelhardt et al. 2010), SynDIG1 (Kalashnikova et al. 2010), neuropillin and tolloid-like proteins Netol and Neto2 ( Ng et al. 2009; Zhang et al. 2009), and Caenorhabditis elegans SOL-1 (Zheng et al. 2004). Studies in tissue culture and heterologous systems suggested that some of the auxiliary subunits have the potential to contribute to clustering of iGluRs, since they promote the accumulation of receptors at the cell surface (for review, see Jackson and Nicoll 2011). However, no auxiliary protein has been implicated in the clustering of iGluRs in vivo. In fact, it is unclear whether surface iGluRs must be associated with auxiliary subunits to be functional. For C. elegans, auxiliary subunits are essential for functional receptors, but for vertebrate and Drosophila iGluRs, this remains an open question.

Drosophila has several genes reported to encode for auxiliary subunits, including a stargazin-type molecule (Stg1) (Liebl and Featherstone 2008), two cornichon proteins (cni and cnir), the SOL-1-related protein CG34402 (Walker et al. 2006), and one Neto-like protein. Among them, we found that neto mRNA is expressed in the Drosophila striated muscle. Similar to vertebrate Neto1 and Neto2, Drosophila Neto is a multidomain, transmembrane protein with two extracellular CUB (for complement C1r/C1s, UEGF, BMP-1) domains followed by an LDLa (low-density lipoprotein receptor domain class A) motif. Unlike vertebrate Netos, we found that Drosophila neto is an essential locus: neto-null embryos are completely paralyzed and cannot hatch into the larval stages. Flies with suboptimal Neto levels, such as in neto hypomorphs, do not fly and have defective NMJ structure and function. We found that Neto is essential in the striated muscle for the synaptic trafficking and clustering of the iGluRs at the PSDs. Moreover, Neto and iGluR synaptic clustering depend on each other. We propose that Neto functions as an essential nonchannel component of the iGluR complexes at the Drosophila NMJ.

\section{Results}

Neto provides an essential function in the Drosophila striated muscles

The available cDNA (GH11189) for the Drosophila neto locus (CG32635) predicts that Neto protein has a topology similar to the longest vertebrate Neto isoforms. It contains two extracellular CUB domains, followed by an LDLa motif, a transmembrane pass, and a 240-amino-acid intracellular domain (Fig. 1A). The homology with the vertebrate Netos (Neto1 and Neto2) is mostly restricted to the extracellular domains: $35 \%$ similarity and $24 \%$ identity with Neto1, and 33\% similarity and 19\% identity with Neto2. A stretch of $\sim 80$ residues before the first CUB domain is present only in Drosophilidae (Supplemental Fig. S1). The intracellular part of Neto is less conserved and does not contain a PDZ-binding motif. However, it displays numerous potential sites for phosphorylation like vertebrate Netos.

To study the function of the Drosophila Neto, we generated an allelic series of mutations using transpos- 


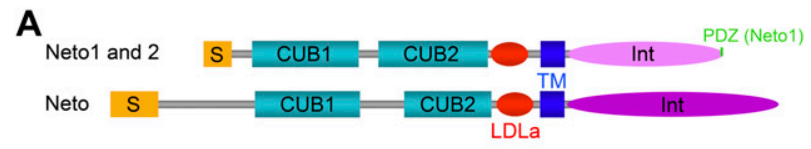

B
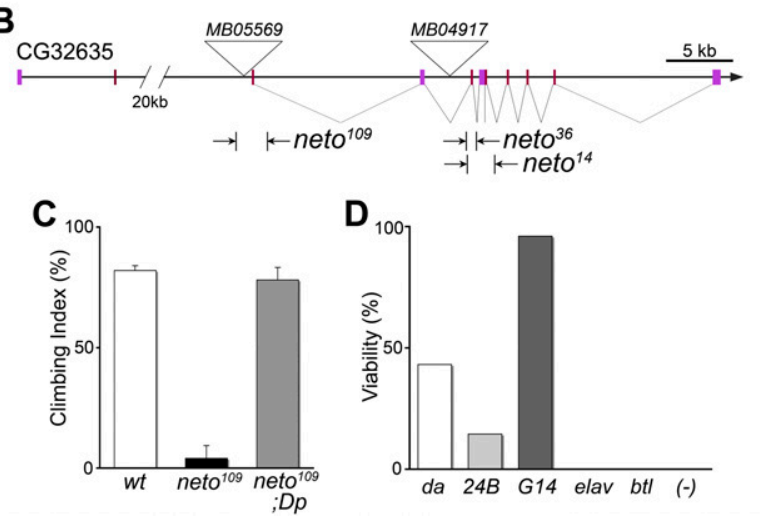

Figure 1. Drosophila Neto is essential for muscle function. $(A)$ Alignment of vertebrate Neto1 and Neto2 and Drosophila Neto indicates their similar domain organization. All Neto proteins contain a signal peptide (S), followed by two extracellular protein-protein interaction domains (CUB) and an LDLa motif. The percentages of similarity/identity are as follows: CUB1 domain, $82 \% / 64 \%$ between mouse Netol and Neto-2, and 54\%/ $41 \%$ between fly and mouse Netos; CUB2 domain, $87 \% / 72 \%$ and $41 \% / 21 \%$; LDLa, $89 \% / 83 \%$ and $50 \% / 31 \%$. The intracellular domain is less conserved $(53 \% / 39 \%$ and $24 \% / 9 \%)$. (B) Schematic view of the neto locus and the small deletions generated. The predicted neto locus has 11 exons spanning a $73-\mathrm{kb}$ region. Small deficiencies were generated by imprecise excisions of transposomal elements located within the neto locus (MB05569 and MB04917). (C) Climbing index in flies of indicated genotypes. Flies were placed at the bottom of test vials and monitored for their climbing abilities within $10 \mathrm{sec}$. Most neto ${ }^{109}$ escapers remained at the bottom of the test vials. (D) Percent of rescue of neto ${ }^{36}$ embryos into the larval stages by tissue-specific neto expression. The embryonic lethality of neto ${ }^{36}$ mutants was rescued by ubiquitous expression of the $U A S$-neto-V5 transgene (da-Gal4) and by expression in muscles (24B-Gal4 and G14-Ga14), but not by expression of Neto in neurons (elav-Gal4) or trachea (btl-Gal4).

able elements located within the neto locus (Fig. 1B). Several imprecise excision lines were isolated and were molecularly characterized by PCR amplification and sequencing (Materials and Methods). neto ${ }^{109}$ lacks the start codon-containing exon and shows 50\% pupal lethality under optimal culturing conditions. The adult escapers appear morphologically normal and are fertile, but cannot fly and have severe locomotor defects. These flies could not straighten themselves from an upside down position and showed impaired walking behavior (Fig. 1C). Western analysis with an antibody to the first CUB domain indicated that Neto protein was reduced to $\sim 40 \%$ of the wild-type level in neto ${ }^{109}$ third instar larval muscle tissue (Supplemental Fig. S2). Neto has a calculated molecular weight of $76 \mathrm{kDa}$ but an apparent molecular weight of $\sim 100 \mathrm{kDa}$, likely because of posttranslational protein modifications. The Neto variant in the neto ${ }^{109}$ larvae was indistinguishable by size from the wild-type Neto and could be due to alternative splicing or cryptic start codons. RT-PCR analyses of neto ${ }^{109} \mathrm{mRNA}$ recovered only one truncated neto cDNA, without the exon deleted in neto ${ }^{109}$ (data not shown). Expression of full-length and truncated Neto-GFP in S2 insect cells showed reduced expression of the truncated Neto-GFP relative to wild type. Moreover, the truncated protein was not confined to the secretory compartments and appeared localized at the plasma membrane (Supplemental Fig. S2). Limited amounts of Neto in neto ${ }^{109}$ animals or S2 cells precluded further protein analysis.

Deletion of exon 5 (and 6) in lines neto ${ }^{36}$ and neto ${ }^{14}$ introduced frameshifts and early stop codons. In both cases, the Neto ORF is truncated within the first CUB domain; thus, these lines likely represent genetic-null alleles. neto ${ }^{36}$ and neto ${ }^{14}$ hemizygous embryos had normal overall appearances and completely filled their trachea with gas, but never hatched into the larval stages and died within $2 \mathrm{~d}$ after egg laying (AEL). This phenotype was $100 \%$ penetrant. The mutant embryos were completely paralyzed and lacked any body wall peristalsis and hatching movements (Supplemental Movies). Manually hatched animals failed to move and feed. Similar complete paralysis has been described for mutants with defects in epithelial integrity or with nonfunctional NMJ (Schulze et al. 1995; DiAntonio et al. 1999; Featherstone et al. 2005; Qin et al. 2005; Schwabe et al. 2005; Rohrbough et al. 2007).

Since Neto is expressed in multiple embryonic tissues, including epithelia, CNS, and muscles (data not shown), we tested whether tissue-specific expression of neto transgenes could rescue the lethality of neto ${ }^{36}$ embryos. We found that Neto activity is essential in the muscle, since the lethality of neto ${ }^{36}$ embryos was completely overcome by muscle expression of full-length neto cDNA (UAS-neto) (Fig. 1D). Moreover, a number of animals were rescued all the way to viable and fertile adults using muscle-specific G14-Gal4 and 24B-Gal4 drivers (Aberle et al. 2002). The lethality of neto ${ }^{36}$ was also completely rescued by a duplication covering the neto locus, $D p(1 ; 3)$ DC270 (Venken et al. 2010). This duplication also rescued the defects in flight and climbing abilities of the neto ${ }^{109}$ hypomorphic allele (Fig. 1C). Thus, the lethality and the locomotion phenotypes observed in our allelic series were due to disruptions at the neto locus, which is essential for the function of the striated muscle in flies.

\section{Neto localizes to the NMT}

Within the striated muscle, Neto localized in distinct puncta at both type I boutons (Ib and Is) in the third instar larvae (Fig. 2A). We could also detect very weak Neto immunoreactivity at the type II boutons, but not at the type III peptidergic boutons (Supplemental Fig. S3A). Thus, Neto localization overlaps with the glutamatergic synapses of the Drosophila NMJ. Neto protein clustered junctionally in late embryonic stages and remained present at the NMJ throughout the larval stages (Fig. $2 \mathrm{~B}, \mathrm{C})$. Low level of Neto immunoreactivity was also detected extrajunctionally in a striped pattern adjacent 

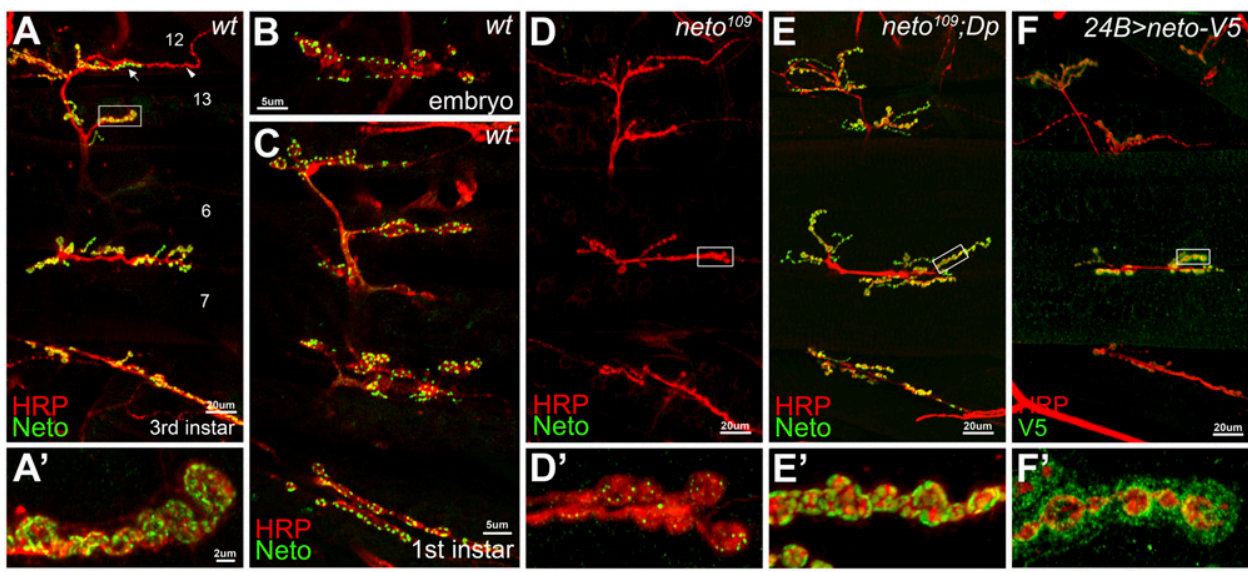

Figure 2. Neto localizes to NMJ. $(A-C)$ Neto localizes in distinct puncta at the NMJ of third instar larvae $(A)\left(\right.$ detail in $\left.A^{\prime}\right)$, late embryos $(B)$, and first instar $(C)$. The anti-HRP antibody (red) labels all motor neuron arbors. The anti-Neto antibody (green) labels predominantly the type I boutons at all NMJ synapses during embryonic and larval stages of development. (Arrow) Type I boutons; (arrowhead) type II boutons. $(D, E)$ Synaptic localization of Neto is disrupted in neto ${ }^{109}$ third instar larvae $(D)$, but is restored by a duplication covering the neto locus $(E) .\left(D^{\prime}, E^{\prime}\right)$ Details of sections boxed in $D$ and $E$. Representative large fields of muscles 6/7 and 12/13 from the indicated genotypes are compared. $(F)$ Muscle-expressed Neto-V5 (green) localizes at the synapses and is distributed in puncta concentrated near the motor neuron arbor (labeled with anti-HRP in red). Excess Neto-V5 accumulates on the muscle membrane in a hollow surrounding the boutons, likely the SSR membrane folds (detail in $F^{\prime}$ ), and in a striped pattern throughout the muscle fiber.

to the F-actin-labeled $\mathrm{Z}$ discs and restricted to the exterior part of the muscle (Supplemental Fig. S3B). This striped pattern is reminiscent of the $T$ tubules of striated muscles.

The level of Neto detected in the muscle of neto ${ }^{109}$ larvae was significantly reduced, but was restored by introducing a duplication that covers the neto locus (Fig. 2D,E). Muscle-expressed Neto tag chimeras also localized at the NMJ, mainly at the type I boutons (Fig. 2F). The presence of various C-terminal tags (eGFP or V5) did not interfere with the junctional localization of Neto or with its ability to rescue various neto alleles when expressed in the muscle (below). However, NMJ synapses in larvae with elevated levels of Neto in the muscle were reduced in growth and showed a more diffuse localization of Neto chimeras at the postsynaptic side (Fig. 2F; Supplemental Fig. S3C).

\section{Neto colocalizes with iGluR receptors at the PSD in puncta juxtaposing the active zones}

Various pre- and postsynaptic markers were used to probe the subcellular localization of Neto at the larval NMJ. Dlg is the primary postsynaptic scaffolding protein and localizes to the subsynaptic reticulum (SSR), a stack of thin folded extensions of the muscle fiber that underlies the postsynaptic cell membrane of the type I boutons and flanks the PSDs (Lahey et al. 1994). Neto-positive puncta were surrounded by but did not colocalize with Dlg, suggesting that Neto localizes at the PSDs (Fig. 3A). Dlg distinguishes between the type $\mathrm{Ib}$ and type Is boutons according to their SSR thicknesses. Neto was present at both type $\mathrm{Ib}$ and Is boutons and appeared more concentrated at the type Is boutons (Fig. 3A).

PSDs comprise a myriad of proteins that concentrate and stabilize the receptors opposite to the site of neurotransmitter release: the active zone. At PSDs, Neto colo- calized with the essential GluRIIC subunit (Fig. 3B). Neto also colocalized with nonessential subunits GluRIIA and GluRIIB (Fig. 3C,D). The Neto immunoreactivity seems to exceed the locations for either IIA or IIB subunits and
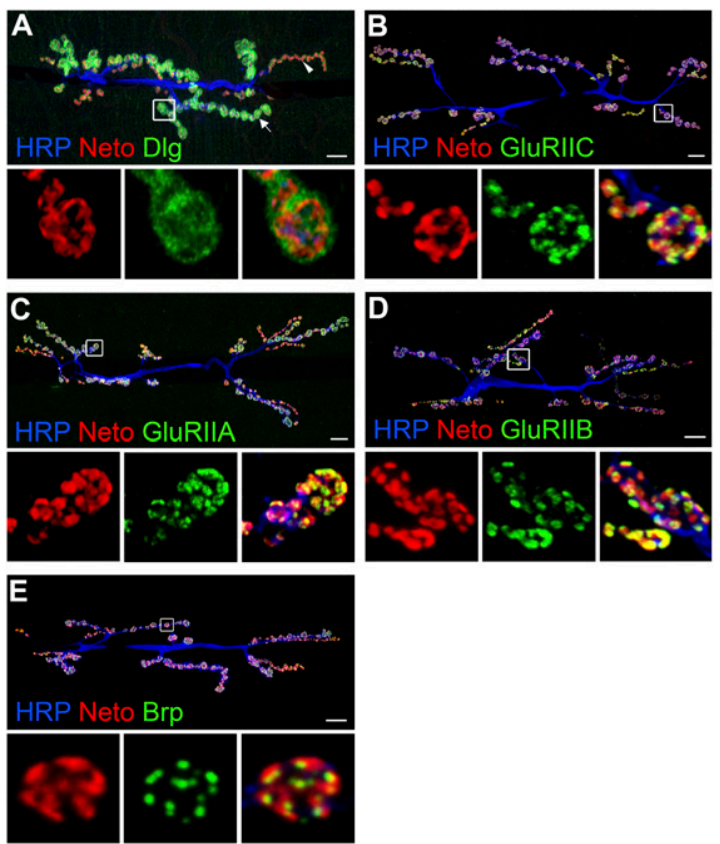

Figure 3. Postsynaptic localization of Neto. $(A-D)$ Neto-positive puncta are surrounded by $\operatorname{Dlg}(A)$ and colocalize with the iGluRs at the PSDs GluRIIC $(B)$, GluRIIA $(C)$, and GluRIIB $(D)$. (E) Neto-positive puncta juxtapose the Brp-labeled active zones, where the neurotransmitter vesicles are released. Confocal stacks of NMJ 6/7 of abdominal segment A2 are shown in all panels, except for the bouton details, which contain very few sections through the boxed boutons. Bar, $10 \mu \mathrm{m}$. 
appears to encompass both of them. The postsynaptic junctional clusters of glutamate receptors juxtapose the active zone. Bruchpilot (Brp), the Drosophila homolog of the vertebrate active zone protein ELKS /also known as CAST and ERC), is present in presynaptic structures that surround and delineate each active zone (Wagh et al. 2006). Like glutamate receptors, Neto-positive puncta juxtaposed to the sites of neurotransmitter release, which were visualized with an anti-Brp antibody (NC82) (Fig. 3E). In fact, every Brp-positive puncta within a bouton was accompanied by a Neto-positive aggregate similar in shape to the receptor fields. Together, our data indicate that Neto localizes to the PSDs in puncta juxtaposing the active zones and overlapping with type $\mathrm{A}$ and $\mathrm{B}$ glutamate receptor complexes.

\section{Neto is required for synaptic function}

Both the synaptic localization of Neto and the behavioral defect of the neto mutant flies suggest that Neto plays an important role in the function of the nervous system and/ or the musculature. To test this hypothesis, we recorded evoked excitatory junctional potentials (EJPs) and spontaneous miniature potentials (mEJPs, or minis in short) from muscle 6 of third instar larvae. In control larvae (wild type), the mini occurs six times per second on average (Fig. 4A,B). This was reduced to 0.3 events per second in neto ${ }^{109}$ animals. The defects in mini frequency were rescued in neto ${ }^{109} /$ neto $^{36}$ trans-allelic combinations or in neto ${ }^{36}$ embryonic-lethal animals by a neto-containing duplication or by muscle-specific expression of UAS-neto (Fig. 4B; data not shown). Mini amplitude, a product of the amount of glutamate released from a single vesicle and the number of receptors receiving the transmitter, was reduced in neto ${ }^{109}$ (Fig. 4C). This defect was also fully rescued by the neto duplication in trans-allelic animals. Importantly, the reduction in mini amplitude occurs in mutant muscles that have no change in both resting potential and input resistance.

The dramatic reduction of mini frequency and amplitude is reminiscent of mutations in iGluRs (Petersen et al. 1997; DiAntonio et al. 1999; Marrus et al. 2004; Featherstone et al. 2005; Qin et al. 2005). The reduction in mini frequency could result from defects in (1) the presynaptic release probability, (2) the number and density of postsynaptic iGluRs, (3) silent synapses, and (4) amplitude-reduced minis undetectable above the noise levels. To distinguish the first two possibilities, we monitored the amplitude of evoked EJPs and quantal content. The amplitude of evoked EJPs was reduced in neto ${ }^{109}$ third instar larvae (Fig. 4D,E). A much more dramatic defect is anticipated in neto ${ }^{36}$-null mutations, but recording from these animals was not performed because they die as embryos and contain essentially no cluster of iGluRs (see below). Quantal content, a ratio of average EJP amplitude to the mEJP amplitude, is used to estimate the number of vesicles fused in response to each action potential. Since data were recorded at relatively high $\mathrm{Ca}^{2+}$ concentration, we first applied corrections for nonlinear summation (Stevens 1976; Feeney et al. 1998; Lagow et al. 2007). Consistent with a reduction in both mini and EJP amplitudes, quantal content remains unaltered in neto ${ }^{109}$ mutant NMJs compared with wild-type controls (Fig. 4F). Hence, our physiology studies suggest that reduced Neto levels significantly impair the number and density of postsynaptic iGluRs without an apparent effect on presynaptic release. In contrast, GluRIIA and GluRIIC mutations exhibit enhanced presynaptic release and substantial homeostatic compensation (Petersen et al. 1997; DiAntonio et al. 1999; Marrus et al. 2004).

\section{Neto is essential for iGluR clustering}

The complete paralysis and embryonic lethality observed in the neto ${ }^{36}$ mutant animals are reminiscent of phenotypes described for mutants in essential subunits of the iGluR complexes. Furthermore, our physiological analysis indicates a defect in iGluR number and density. Since Neto localized together with the iGluRs at the PSDs, we asked whether Neto could play a role in the formation of receptor clusters during synaptogenesis. Previous studies demonstrated that low levels of iGluRs are present
A
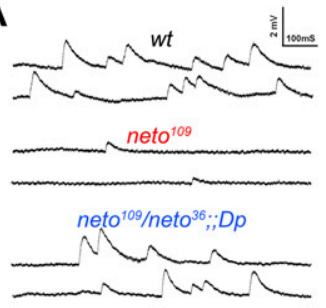

D

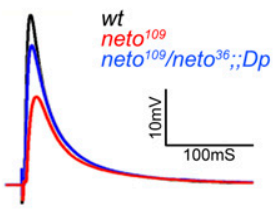

B
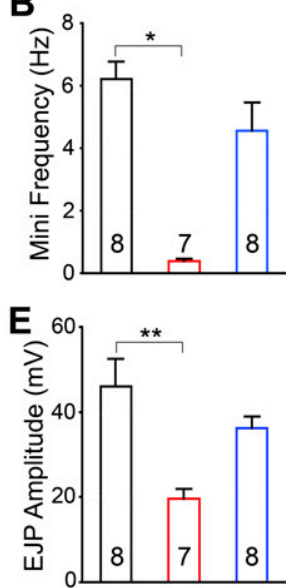
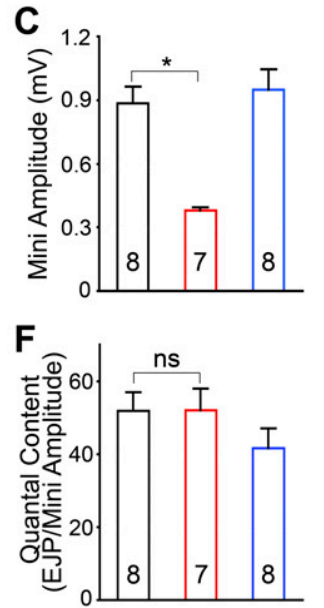

Figure 4. Neurotransmission in neto mutants can be rescued by muscle expression of Neto. $(A)$ Representative traces of spontaneous mEJPs from wild-type larvae (wt), neto ${ }^{109}$ larvae, and neto ${ }^{109} /$ neto $^{36}$ larvae rescued with duplication. Note the reduction in both mini frequency and amplitude in neto ${ }^{109}$ larval NMJs. The muscle resting potential and input resistance are not affected by the neto mutations. $(B, C)$ Bar graph presentation of mean values for $\mathrm{mEJP}$ from wild-type larvae (black), neto ${ }^{109}$ larvae (red), and neto ${ }^{109} /$ neto $^{36}$ larvae rescued with duplication (blue). (B) mEJP frequency. $(C)$ mEJP amplitude. $\left({ }^{*}\right) P<0.001$. Error bars denote \pm SEM. $(D)$ Representative traces of evoked EJPs from the indicated genotypes. The $\mathrm{Ca}^{2+}$ concentration was $0.8 \mathrm{mM}$ in HL-3 saline. $(E, F)$ Bar graph presentation of mean values for EJP amplitude $(E)$ and quantal content $(F)$ from wild-type larvae (black), neto ${ }^{109}$ larvae (red), and neto ${ }^{109} /$ neto $^{36}$ larvae rescued with duplication (blue). $\left.{ }^{* *}\right) P<0.05$. 
diffusely in the muscle membrane before a muscle is innervated. Soon after the motoneuron growth cone contacts the muscle, iGluRs begin to concentrate at the synaptic cleft (Broadie and Bate 1993b). Small, nascent glutamate receptor complexes were abundant in the vicinity of the $\mathrm{NMJ}$ in both neto ${ }^{36}$ heterozygous and hemizygous embryos (Fig. 5A). However, clusters of glutamate receptors at the presynaptic arbors were detected only in heterozygous embryos, while in hemizygous animals, these clusters were significantly reduced in number and size and remained relatively far away from the presynaptic arbors (GluRIIA shown in Fig. 5A). The small clusters visible in neto ${ }^{36}$ hemizygous embryos likely represent nascent glutamate receptor complexes.

These defects were not caused by improper axon guidance or adhesion, since the pre- and postsynaptic partners appeared properly aligned in neto ${ }^{36}$ mutants. Moreover, the synapse prepatterning, including the accumulation of presynaptic Brp and postsynaptic P21-activating kinase (PAK) clusters, appeared normal (Fig. 5B). Thus, the initial structure of the synapse is prepatterned in the absence of Neto, similar to the normal prepatterning observed in the absence of iGluRs (Schmid et al. 2006).

The iGluR clustering as well as the embryonic lethality of neto ${ }^{36}$ hemizygous embryos were rescued when Neto was expressed in the striated muscle (Figs. 1D, 5A). In fact, rescued animals appeared to have a slightly in-
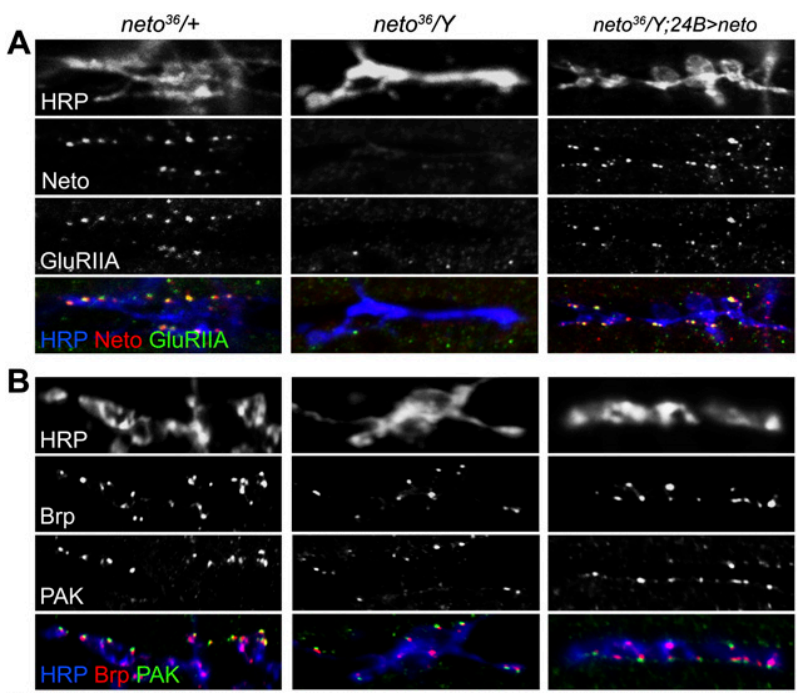

Figure 5. iGluRs do not cluster in the absence of Neto. $(A)$ GluRIIA clustering in embryos of indicated genotypes at $21 \mathrm{~h}$ AEL. The GluRIIA receptor subunit (green) clusters in neto ${ }^{36} /+$ heterozygous (left) but not in neto ${ }^{36} / Y$ hemizygous (middle) embryos. (Right) The GluRIIA clustering is restored in neto ${ }^{36} / Y$ mutant animals when Neto is provided in the muscle. The antiHRP antibody (blue) labels all motor neuron arbors. (B) Despite the absence of the iGluRs and Neto at the synapses, neto ${ }^{36} / Y$ hemizygous embryos (shown in the middle panel) still show accumulations of the PSD marker PAK (green) opposite to presynaptic release sites labeled with anti-Brp (red). Clustering of Brp and Pak are similar for all genotypes tested: neto ${ }^{36} /+$ heterozygous (left), neto ${ }^{36} / Y$ hemizygous (middle), and neto ${ }^{36} / Y$ hemizygous animals rescued by muscle expression of Neto-V5 (right). creased number of smaller, nascent glutamate receptor clusters at presynaptic arbors and additional small clusters nearby. The apparent increase in the number of clusters and their relatively smaller size could be due to overexpression of Neto in the muscle and initiation of more receptor aggregates at early stages of synaptogenesis. Later on, in third instar stages, we found no proportional increase in the number of receptor puncta (data not shown), perhaps due to subsequent mechanisms that may compensate for the initial increase in the number of nascent clusters and adjust the growth of the NMJ.

The extent of iGluR clustering at the NMJ was also markedly reduced later in development in neto ${ }^{109}$ hypomorphic mutants (Fig. 6A). Significant reduction in iGluR labeling intensity at the normal junctional location was observed, accompanied by an increase of ectopic localization of iGluRs as extrasynaptic aggregates scattered throughout the neto ${ }^{109}$ muscle. The wild-type/neto ${ }^{109}$ pairs were imaged under the same conditions to capture and compare the synaptic and extrasynaptic immunoreactivities. Under these settings, the junctional GluRIIA, GluRIIB, and GluRIIC clusters in neto ${ }^{109}$ third instar larvae were drastically reduced, and their extrasynaptic distribution was clearly visible (Fig. 6A,B; Supplemental Fig. S4). The nature and composition of these extrajunctional immunoreactivities could not be further defined in our colocalization experiments, although extrasynaptic GluRIIA staining generally appeared adjacent to but not overlapping with GluRIIC (data not shown). More importantly, the levels of the receptors-in this case, GluRIIBwere unchanged, as seen in Western analysis (Fig. 6C). Thus, suboptimal Neto levels limit the synaptic localization of the iGluR complexes and alter their subcellular localization toward extrasynaptic locations. Interestingly, Neto itself formed a severely reduced number of junctional clusters, and these clusters always colocalized with iGluRs (Fig. 6B; Supplemental Fig. S4). A similar reduction of Neto-iGluR junctional clusters was observed in neto ${ }^{109} /$ neto $^{36}$ trans-allelic third instar larvae (GluRIIA shown in Supplemental Fig. S4). The two alleles were generated in different genetic backgrounds and exclude any unrelated defects.

To determine whether suboptimal levels of Neto affected other PSD components, we examined PAK, which stabilizes postsynaptic components at the NMJ in larval stages and regulates the size of the SSR (Parnas et al. 2001). PAK serves as a PSD marker at NMJ synapses and strictly colocalizes with the GluRIIA subunit (Rasse et al. 2005). The intensity of PAK signals at individual PSDs was strongly reduced in neto ${ }^{109}$ third instar larvae (Fig. 6D). The presence of PAK synaptic clusters at the prepatterning stage in neto-null embryos and PAK diminution in Neto-deprived larvae suggest a deficit in the maintenance of mature PSDs in neto mutants. A similar deficit was reported for NMJ synapses developing in the near absence of iGluRs (Schmid et al. 2006). In contrast, the presynaptic release sites appeared normal at suboptimal levels of Neto or iGluRs. We examined the active zones and found that junctional Brp staining was normal, with a relatively equal number of Brp-positive puncta in the neto ${ }^{109}$ third 

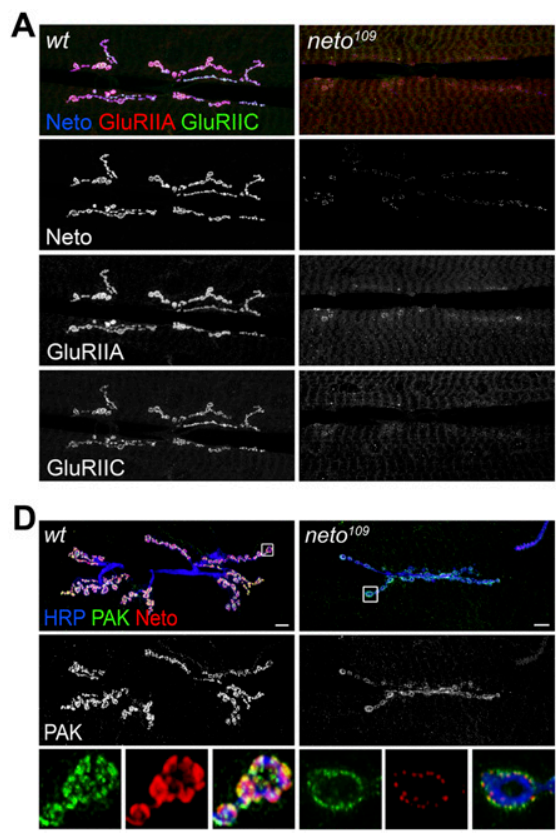
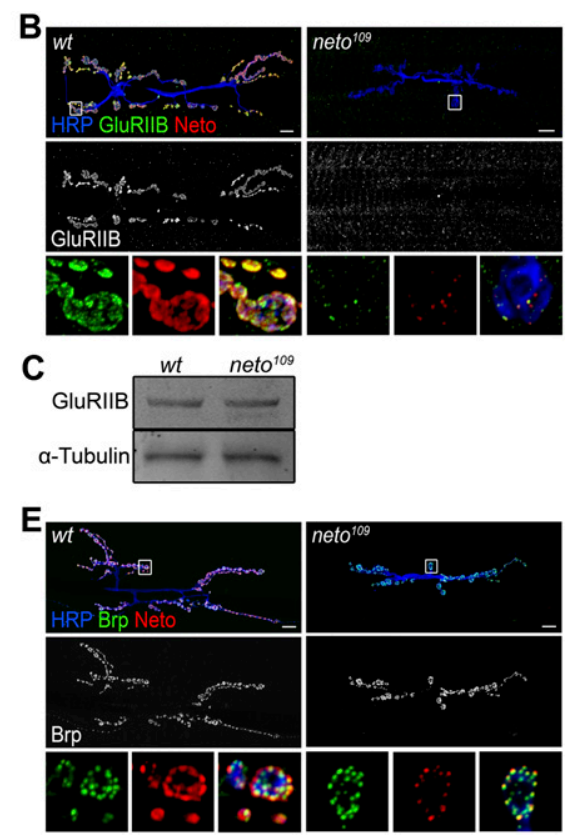

Figure 6. Postsynaptic localization of iGluRs is impaired at reduced Neto levels. (A) GluRIIA and GluRIIC immunoreactivites are shifted from postsynaptic clusters in wild type (wt) to mostly extrajunctional locations in neto ${ }^{109}$ third instar larvae. $(B)$ GluRIIB postsynaptic clusters are also disrupted in neto ${ }^{109}$ larvae and appear shifted from junctional to extrajunctional locations. The few remaining synaptic GluRIIB puncta (green) are always accompanied by Neto puncta (red) at the motor neuron arbor (blue). (C) Western blot comparison of GluRIIB protein levels in wild-type and neto ${ }^{109}$ larval muscle. $\alpha$-Tubulin was used as a loading control. $(D)$ The synaptic accumulation of PAK (green) is diminished in neto ${ }^{109}$ larvae as compared with the wild type, but the postsynaptic PAK-positive puncta mostly colocalize with the Netopositive puncta (red). (E) The intensity and distribution of the presynaptic active zone marker Brp appear to be normal in neto ${ }^{109}$ larvae versus wild type. The intensities and numbers of Brp puncta per bouton are largely similar in wild type and neto ${ }^{109}$. (Right) Note the reduced size of Neto-positive puncta. The Neto-positive clusters are still juxtaposing Brp-positive active zones in neto ${ }^{109}$ larvae. Representative fields at muscles $6 / 7$ of abdominal segment A2 from the indicated genotypes are compared. Bar, $10 \mu \mathrm{m}$.

instar larvae versus wild type (Fig. 6E). The synaptic vesicle organization and density appeared largely unaffected in neto ${ }^{109}$ third instar larvae, as shown by analysis of synaptic vesicle marker cysteine string protein (CSP), which labels clusters of synaptic vesicles in the vicinity of the presynaptic membrane (Supplemental Fig. S5). These results are consistent with our physiological data indicating that presynaptic release is not altered in neto mutants.

\section{Neto is required for NMI synapse development}

On the postsynaptic side, the synaptic accumulation of Dlg was substantially and consistently reduced in neto ${ }^{109}$ third instar larvae (Fig. 7A). In fact, the Dlg distribution was so diminished that type Ib and Is boutons became indistinguishable. The reduced Dlg accumulation at the SSR in the muscles of neto ${ }^{109}$ larvae was not caused by a reduction of Dlg protein levels (Fig. 7B), but rather by a redistribution of Dlg at extrajunctional locations (Fig. 7A, middle panel). The Dlg accumulation at the SSR was restored in neto ${ }^{109}$ or trans-allelic combinations by a duplication covering the neto locus (Fig. 7A). Thus, the reduction of Neto protein levels in neto ${ }^{109}$ correlates with altered Dlg, iGluR, and PAK distributions and an apparent shift of immunoreactivity from junctional to extrajunctional locations. This is consistent with a deficit in the recruitment and stabilization of postsynaptic components.

Furthermore, both the quantity and the morphology of the synaptic boutons were altered at reduced Neto levels. We counted the total number of type I boutons at the muscle $6 / 7$ cleft in multiple abdominal segments in neto ${ }^{109}$ third instar larvae and found that $60 \%$ reduction in the Neto protein level corresponds to up to $40 \%$ re- duction in the total number of type I boutons (Supplemental Fig. S6). The number of synaptic boutons was rescued in neto ${ }^{109}$ or neto ${ }^{109} /$ neto $^{36}$ trans-allelic combinations by a duplication covering the neto locus. The synaptic boutons appeared to have abnormal, irregular shapes in neto ${ }^{109}$ mutants under both light and electron microscopy. Under electron microscopy, active zones in wild-type synapses are marked by electron-dense membranes and presynaptic specialization called $\mathrm{T}$ bars (Fig. 7C). The electron-dense membrane regions are greatly reduced or strikingly absent in neto mutants. This phenotype is restricted to the synaptic cleft and postsynaptic compartment, since normal $\mathrm{T}$ bars are present presynaptically at mutant synapses lacking electron-dense membranes. The pre- and postsynaptic membranes are in tight and close apposition in wild-type synaptic boutons, but are sinuous and often detached in neto mutants. A thick stack of SSR folds underlies the postsynaptic cell membrane of the type Ib boutons. In neto ${ }^{109}$ mutants, the SSR folds are no longer stacked against each other and instead form a sparse and lacey halo around the type Ib boutons. The overall width of the SSR appears largely unaffected, but its boundaries are disorganized, particularly the apposition to the muscle contractile tissue. Thus, the postsynaptic domains, including SSR, exhibited grossly abnormal ultrastructural profiles in neto mutants.

To test whether the disruption of iGluR clustering and Dlg accumulation at the SSR at reduced Neto levels was due to a general cytoskeletal disorganization, we examined the pre- and postsynaptic cytoskeleton in neto ${ }^{109}$ third instar larvae. Futsch/MAP1b-positive presynaptic microtubules remain organized in smooth sheaths and loops in neto ${ }^{109}$ larvae, similar to wild type (Supplemen- 
A

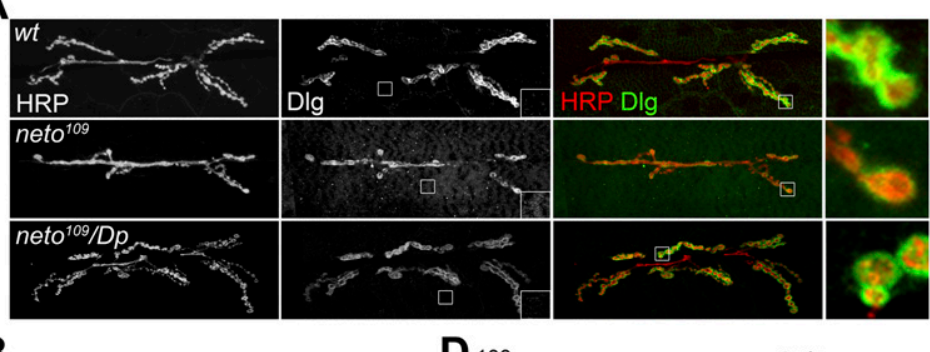

B

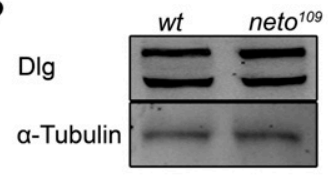

C

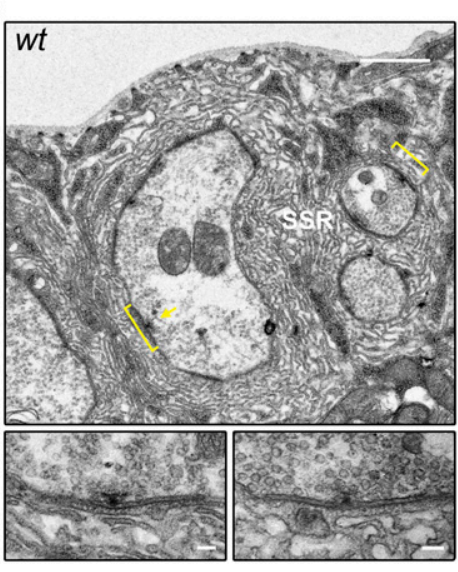

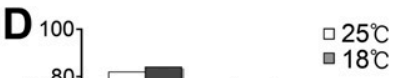
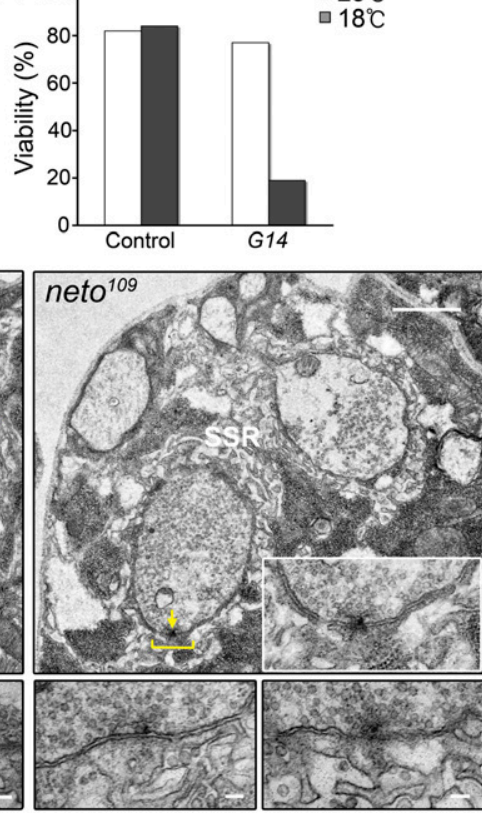

Figure 7. NMJ synapse development is altered at reduced Neto levels. $(A)$ Postsynaptic Dlg accumulation is shifted from junctional to extrajunctional location in neto ${ }^{109}$ larvae as compared with wild type (wt) (details in insets). Note the reduced Dlg staining at the type Ib boutons (details in the last column) and the absence of Dlg staining at the type Is boutons. (Bottom panels) Synaptic accumulation of $\mathrm{Dlg}$ is restored by a duplication covering the neto locus. Representative fields at muscles 6/7 of abdominal segment A2 from the indicated genotypes are compared. $(B)$ Western blot comparison of $\mathrm{Dlg}$ protein levels in wild-type and neto ${ }^{109}$ larval muscle. $\alpha$-Tubulin was used as a loading control. $(C)$ Electron micrographs of synaptic boutons from wild-type (left) and neto ${ }^{109}$ (right) third instar larvae. SSR, T bars (arrows), and PSDs (brackets) are indicated. The SSR is densely packed around wild-type type Ib boutons, but is sparse in neto ${ }^{109}$ mutants. At wild-type synapses, $\mathrm{T}$ bars are juxtaposed by electron-dense structures in the synaptic cleft and postsynaptic domain. In contrast, the neto ${ }^{109}$ mutant synapses display a loss of electron-dense membrane domains (detail). The pre- and postsynaptic membranes are sinuous and appear disorganized in neto ${ }^{109}$ mutants as compared with the tight and close apposition of wild-type synaptic membranes. Bar, $1 \mu \mathrm{m}$; in details, $0.1 \mu \mathrm{m}$. $(D)$ Percent of adults emerging from neto ${ }^{36}$-null embryos after a pulse of Neto expression. Control $\left(\right.$ neto $\left.^{36} /+; G 14 /+\right)$ or rescued $\left(\right.$ neto $^{36} / Y$; G14>UASg-Neto-GFP) animals were reared at $25^{\circ} \mathrm{C}$ during the embryo stages. The first instar larvae were kept at the indicated temperatures, and the percentages of adults emerging were plotted. When reared at $18^{\circ} \mathrm{C},<20 \%$ adults hatched. Most of the animals that received a pulse of Neto expression only during embryogenesis died during larval and pupal stages. In contrast, at $25^{\circ} \mathrm{C}$, most of the rescued animals lived to adulthood. tal Fig. S5). However, $\alpha$-spectrin, which labels the presynaptic axon and surrounds the bouton postsynaptically overlaping with Dlg (Pielage et al. 2005), is reduced in intensity at the postsynaptic side in neto ${ }^{109}$ third instar larvae (Supplemental Fig. S5). The reduced postsynaptic $\alpha$-spectrin appears to be a consequence and not a cause of the disorganized PSDs, likely because of its role in stabilizing type A iGluR complexes. At the postsynaptic side, $\alpha$-spectrin interacts with coracle and dystroglycan and together they selectively influence the junctional accumulation of A-type iGluR receptors (Bogdanik et al. 2008). Moreover, elimination of both $\alpha$-spectrin and $\beta$-spectrin produces no electrophysiologically detectable change in postsynaptic glutamate receptors (Featherstone et al. 2001), while reduced Neto severely impairs them. We concluded that Neto plays no role in organizing the presynaptic microtubules or synaptic vesicles and release sites and instead functions in clustering of iGluRs and in stabilizing the PSDs.

Since Neto and iGluRs appear to cluster together at the beginning of synaptogenesis, we wondered whether the defects and lethality of neto ${ }^{109}$ could be solely a consequence of inadequate Neto activity during embryonic stages at the onset of receptor clustering. To test this possibility, we took advantage of the temperature sensitivity of the Gal4 system to provide neto in null mutants during embryogenesis under the control of G14-Gal4. We reared the embryos at $25^{\circ} \mathrm{C}$ and divided the freshly hatched first instar larvae into two classes: one that continued to develop at $25^{\circ} \mathrm{C}$ and one that was reared at $18^{\circ} \mathrm{C}$ for the rest of development. We found that all of the larvae maintained at $25^{\circ} \mathrm{C}$ lived to adulthood $(77 \%, n=100$, $82 \%$ in control), while most of the larvae that were switched at lower temperatures died during larval-pupal stages and failed to reach adulthood (19\% adults hatched, $n=100,84 \%$ in control) (Fig. 7D). A close inspection of the first instar larvae showed that the morphology of rescued synapses was normal (data not shown). The animals reared at $25^{\circ} \mathrm{C}$ appeared morphologically normal in third instar larvae, but limiting the Neto levels at $18^{\circ} \mathrm{C}$ produced altered, smaller synapses. The heterozygote neto ${ }^{36} /+$ siblings reared at $18^{\circ} \mathrm{C}$ develop normally to adulthood; thus, the defects observed cannot be explained by an effect of reduced temperature. Instead, our data indicate that there is a constant need for Neto activity throughout the NMJ development, likely due to a continuous role for Neto in clustering and stabilizing iGluRs at the NMJ.

\section{Neto clustering at the NMJ requires iGluRs}

Previous analyses of NMJ synaptogenesis indicated that iGluRs begin to cluster at synapses as early as $13.5 \mathrm{~h} \mathrm{AEL}$, 
as soon as the growth cones contact the myotubes (Broadie 1999|. Growth cone filopodia restricted to the synaptic site start forming boutons at $15 \mathrm{~h} \mathrm{AEL}$, and an hour later, the muscle initiates de novo expression of iGluRs toward increasing the junctional iGluR density. To explore the timing of Neto clustering at the NMJ, we used live imaging of embryos with muscle-expressed Neto-eGFP (Fig. 8A). Under these conditions, Neto-eGFP significantly accumulates at the NMJ by $16 \mathrm{~h}$ AEL. Some accumulation of NetoeGFP aggregates at the NMJ can be observed as early as $14 \mathrm{~h}$ AEL. Since the appearance of synaptic Neto-eGFP follows Gal4/UAS expression and chromophore folding, we suspect that Neto could begin to cluster at the NMJ
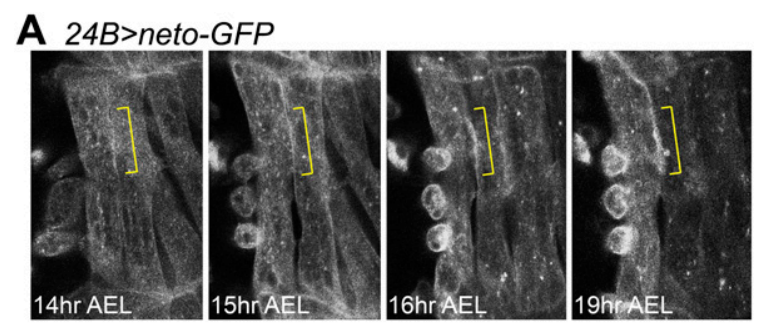

B gluRIID-/+

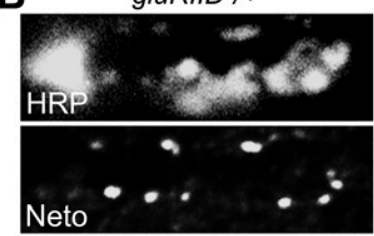

gluRIID -/-
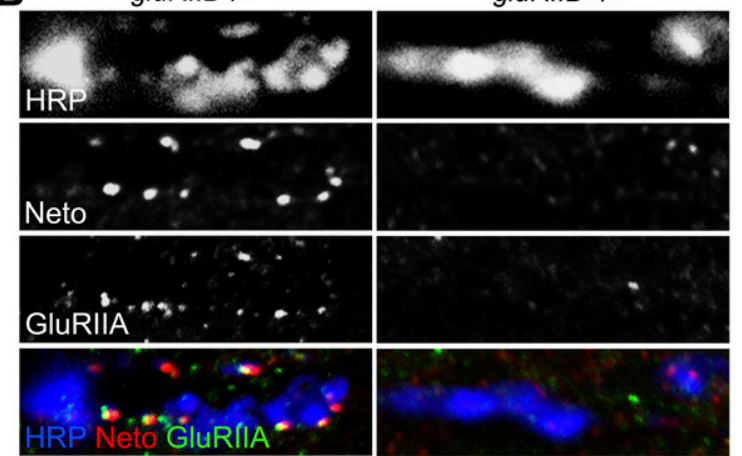

C

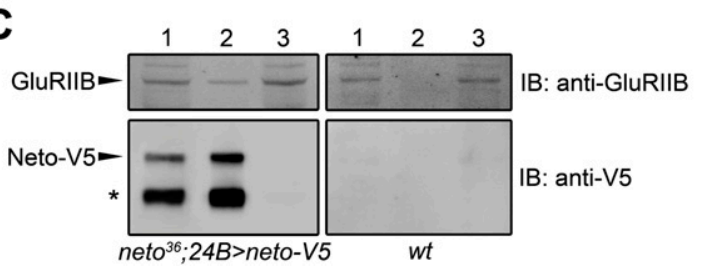

Figure 8. Neto clustering at the NMJ requires iGluRs. (A) Timing of Neto clustering at the NMJ. Neto-GFP was expressed in the muscle (using the muscle-specific promoter 24B-Gal4), and the GFP signal was followed in live embryos. Neto-GFP begins to form clusters at the embryonic NMJ as early as $14 \mathrm{~h}$ AEL. Yellow brackets mark the future NMJ. (B) Neto clustering in embryos of indicated genotypes at $21 \mathrm{~h}$ AEL. Similar to GluRIIA clusters (green), Neto-positive puncta (red) accumulated postsynaptically in gluRIID heterozygous (left) but not in gluRIID homozygous (right) embryos. The anti-HRP antibody (blue) labels all motor neuron arbors. $(C)$ Coimmunoprecipitation of GluRIIB with Neto-V5 from third instar larvae muscles. Soluble muscle fractions were extracted from rescued larvae $\left(\right.$ neto $^{36}$; 24B>neto-V5) (left panel) or wild-type control (right panel), immunoprecipitated with anti-V5, and analyzed by Western. (Lane 1) Input, $5 \%$ of total extract. (Lane 2) Pulled-down fraction. (Lane 3) Unbound fraction. (*) Truncated form of Neto-V5. earlier, at the time when iGluRs cluster at synapses. In fact, the zygotic muscle expression of neto mRNA precedes the events described above (data not shown); thus, the endogenous Neto protein is expected to populate the developing muscles of embryos at $\sim 13 \mathrm{~h}$ AEL. These data suggest that Neto clusters at the NMJ at the time when the iGluR receptors begin to accumulate and cluster at the synapses.

Since the timing of Neto and glutamate receptor initial clustering appears to coincide and the iGluR clustering is dependent on Neto, we asked whether these processes are coupled and therefore dependent on each other. In the absence of any essential receptor subunit (i.e., GluRIID), the iGluR complexes do not cluster at NMJ synapses in late embryos at $21 \mathrm{~h}$ AEL (Fig. 8B; Schmid et al. 2006). More specifically, in gluRIID heterozygote embryos, we observed many GluRIIA-positive puncta of various sizes, with the large clusters also positive for Neto. In gluRIID homozygote embryos, GluRIIA-positive puncta were extremely rare and were never accompanied by Neto immunoreactivity. Most importantly, Neto-positive puncta could no longer be detected in gluRIID homozygote embryos (Fig. 8B). Instead, we occasionally observed very small Neto-positive speckles that never colocalized with iGluRs. These observations indicate that Neto clustering at the NMJ requires intact iGluR complexes. Since the receptors do not cluster in the absence of Neto and Neto does not cluster in the absence of receptors, then Neto and iGluRs must cluster together in a codependent manner. This implies that Neto must associate with the iGluR complexes in vivo. Vertebrate Netos bind directly to selective kainate-type receptor subunits in vivo and in vitro ( $\mathrm{Ng}$ et al. 2009; Zhang et al. 2009). The expectation would be that Neto directly binds to and engages the iGluR complexes. Since Neto antibody does not work in coimmunoprecipitation, we tested this possibility using tagged Neto-V5 constructs and protein extracts from the muscle of rescued larvae. We found that GluRIIB coimmunoprecipitates with Neto-V5 but not with the nontagged control (Fig. 8C). While this result does not demonstrate a direct Neto-iGluRs interaction, it shows that Neto is found in a complex together with the receptors in the larval muscle. Further experiments will be needed to probe for the direct binding and iGluR subunit specificities for Neto. Taken together, our data indicate that Neto functions as a nonchannel, essential subunit of the iGluR complex.

\section{Discussion}

Receptor clustering is crucial for the function of all chemical synapses. Much of what we have learned about receptor clustering comes from studies of nAChRs at the NMJ in vertebrates (for reviews, see Sanes and Lichtman 2001; Wu et al. 2010). We know less about the mechanisms by which iGluRs cluster at the postsynaptic membrane. In this study, we describe the Drosophila Neto as an essential, new component of the iGluR complex; within this complex, Neto and iGluRs depend on each other to traffic and to form clusters at the NMJ. 
Drosophila Neto functions as an essential component of the iGluR complexes

The Drosophila neto is an essential locus that encodes for a protein dynamically expressed throughout development. The neto transcript is maternally loaded, and the protein could be detected by Western analysis at all stages of embryogenesis. In spite of a significant maternal pool, the absence of zygotic neto expression produces $100 \%$ embryonic paralysis and lethality, suggesting a crucial role for Neto in the later stages of embryogenesis. Fully penetrant embryonic paralysis has been described only for two types of mutants: with defects in epithelial integrity or with nonfunctional NMJ. In the first class, disruption of the blood-brain barrier allows for the potassium-rich hemolymph to flood the CNS, causing hyperactivity and action potential failure (Schwabe et al. 2005). The second class includes mutants that impair the NMJ function (Schulze et al. 1995; DiAntonio et al. 1999; Featherstone et al. 2005; Qin et al. 2005; Rohrbough et al. 2007). Muscle expression of Neto rescued the lethality and defects of netonull mutants, indicating an essential role for Neto at the NMJ. Our findings fit best with a model in which Neto and iGluRs are engaged in targeting each other to PSDs via direct interaction. In this model, Neto functions as a nonchannel, essential subunit of the iGluR complexes.

Indeed, neto loss-of-function phenotypes parallel the loss-of-function defects described for iGluR complexes. First, neto-null mutant embryos lack any body wall peristalsis and hatching movements and have no detectable iGluR clusters at the NMJ. Second, the animals with suboptimal Neto levels have a dramatically reduced number of synaptic iGluR clusters and reduced frequency and amplitude of miniature synaptic potentials. The sparse iGluR clusters in neto ${ }^{109}$ always colocalize with Neto clusters (Fig. 6), indicating that the complexes must contain Neto and iGluRs in order to be incorporated at the PSDs. Finally, Neto-deprived animals exhibit a deficit in the maintenance of mature PSDs. A similar deficit was reported for NMJ synapses developing in the near absence of iGluRs (Marrus and DiAntonio 2004; Schmid et al. 2006). During synapse formation, iGluR incorporation into the postsynaptic membrane is critical to enlarge PSDs. By clustering in concert to iGluRs, Neto is essential for functional iGluR complexes and directly controls synapse formation at the Drosophila NMJ. An important difference between neto ${ }^{109}$ and glutamate receptor hypomorpic mutants is that quantal content remains unchanged in neto ${ }^{109}$ and there is no presynaptic compensation, as seen in receptor mutants (Petersen et al. 1997; DiAntonio et al. 1999; Marrus et al. 2004). We do not understand the cause for this difference, but we speculate that the lack of presynaptic compensation in neto mutants may reflect a role for Neto in PSD development and maturation and/or in retrograde signaling.

\section{Postsynaptic activities for Neto}

Similar to other postsynaptic components, Neto is distributed between junctional and extrajunctional locations on the muscle, as assessed by antibody staining. Outside the NMJ, Neto appears tightly associated with the muscle membrane in a pattern reminiscent of the $\mathrm{T}$ tubules. This distribution suggests that Neto could traffic on the muscle surface and perhaps could be mobilized to the junctions as needed. Fully functional iGluR complexes were also detected on the muscle surface at extrajunctional locations (Broadie and Bate 1993a).

One way in which Neto could control the iGluR clustering is by engaging the receptor complexes on the muscle membrane followed by trafficking to the synaptic junction. This model would be consistent with the Neto/iGluR codependence for clustering at the synapse that we described; i.e., only components engaged in a productive complex could traffic and be stabilized at the NMJ. This model also predicts that, at suboptimal Neto levels, iGluRs will accumulate on the muscle surface at extrajunctional locations. Indeed, this seems to be the case, since in neto hypomorphs, we detected GluRIIA on the muscle surface, accessible by antibodies in the absence of membrane-permeable detergents (Supplemental Fig. S7).

In addition, Neto may have a regulatory role in the synaptic targeting of the iGluRs and control the extent of iGluR clustering at the NMJ. Neto may receive and integrate signals about the cellular status and transduce that information into targeting a certain amount of receptors to the synapses. The intracellular domain of Neto is rich in putative phosphorylation sites that may be used to modulate Neto engagement of iGluRs or to connect the complexes with motors and scaffold proteins. Several kinases have been described to control the extent of the iGluR accumulation at the NMJ. Their substrates may include Neto as part of signaling networks that couple cell status to growth of postsynaptic structures.

Live-imaging studies have shown that iGluRs from diffuse extrasynaptic pools stably integrate into immature PSDs, while other postsynaptic proteins remain highly mobile (Rasse et al. 2005). Neto may mediate stable incorporation and stabilization of iGluRs to newly formed PSDs. For example, Neto could promote iGluR aggregation via CUB-mediated self-association and/or extracellular interactions. CUB-containing proteins have been implicated in the formation of acetylcholine receptor aggregates in C. elegans (Gally et al. 2004). In flies and vertebrates, synaptic aggregation of the neurotransmitter receptors at the NMJ does not occur in the absence of innervating neurons (Anderson and Cohen 1977; Broadie and Bate 1993b; Keshishian et al. 1993). In vertebrates, neuronally secreted agrin participates in extracellular interactions that enable receptor clustering and synapse stabilization (McMahan 1990). In Drosophila, the molecular mechanisms that underlie the requirement for innervation to initiate synaptogenesis at the NMJ are not known. A forward genetic screen identified Mind the gap (MTG), a presynaptically secreted protein that appears to organize the extracellular millieu, but it is unclear how MTG could induce postsynaptic differentiation (Rohrbough et al. 2007). Neto may provide an entry point in understanding these requirements. Our data indicate that by controlling the iGluRs clustering, Neto plays a significant role in the organization and maintenance of the PSDs. Although Neto does not have a PDZ-binding motif, it may participate in 
both intracellular and extracellular interactions that help stabilize the PSDs.

Vertebrate Netos bind to and have a profound impact on the properties of selective kainate receptors: They modulate the agonist-binding affinities and the off kinetics, thus determining the characteristically slow rise time and decay kinetics of synaptic kainate receptors (Zhang et al. 2009; Straub et al. 2011a,b). A role for vertebrate Netos in surface expression of kainate receptors or their redistribution between synaptic and extrasynaptic locations is less clear at this time, as it appears to depend on specific kainate receptor subunits, the neurons and tissues analyzed, and/or the genetic background of the knockout mice tested (Ng et al. 2009; Copits et al. 2011; Straub et al. 2011a). Nevertheless, it is possible that Drosophila Neto also modulates the ligand-gated channel properties for iGluRs and shapes the function of synapses at the NMJ.

\section{Neto and iGluRs in flies and mammals}

Recent work from vertebrates changed our view on iGluRs: They are not companionless complexes at the PSDs, but rather dynamic supramolecular signaling complexes that include components that regulate the trafficking, scaffolding, stability, signaling, and turnover of the receptors. The discovery of Neto reveals that Drosophila iGluRs also form multisubunit complexes modulated by auxiliary proteins at the fly NMJ. To our knowledge, Neto is the first auxiliary iGluR subunit described in Drosophila. In vertebrates, Neto and other auxiliary subunits impart diversity and richness to iGluR function, but no auxiliary protein was shown to be essential for in vivo clustering of the receptors. Auxiliary subunits in C. elegans are essential for functional receptors but not for clustering. The fly Neto is the first example of an auxiliary subunit required for iGluR clustering.

An intriguing question is why the requirements for Neto are so different in various species. Neto1/Neto2 double knockout mice have defects in long-term potentiation, learning, and memory but are viable (Tang et al. 2011). More importantly, Neto1 and Neto2 are not essential for iGluR clustering. In contrast, Drosophila neto-null mutants are embryonic-lethal, and Neto is absolutely required for iGluR clustering. This difference could be due to variations in the properties of individual domains of Netos, or it could reflect the diversity among synapse types and the nature and composition of multiprotein complexes where various Netos function. Indeed, there are primary sequence differences among Netos that could translate into functional differences. For example, the LDLa motif in Neto2 binds $\mathrm{Ca}^{2+}$ (Zhang et al. 2009); the fly Neto lacks the conserved residues predicted to chelate $\mathrm{Ca}^{2+}$ ions. The fly Neto has a long insert between the signal peptide and the first CUB motif. In all Neto proteins, the intracellular domain is rich in potential phosphorylations sites, but in flies, this domain is very acidic (pI 3.86), unlike Neto1 (pI 8.28) and Neto2 (pI 6.62). Secreted isoforms have been reported/predicted for vertebrate Netos but not for Drosophila. Instead, a new transmembrane Neto isoform has been recently entered in the fly database (cDNA reference RE42119). This isoform is predicted to share the exons encoding for extracellular and transmembrane parts, but has alternative exons to encode for a basic (pI 9.17) intracellular domain, with no similarity with vertebrate proteins. While the validated fly Neto isoform is sufficient to provide the essential Neto activity at the $\mathrm{NMJ}$, it will be interesting to investigate whether flies use multiple Neto isoforms at the NMJ or alternate them for tissue- or synapse-specific functions.

In flies, Neto is also expressed in subsets of neurons in the CNS (data not shown); thus, Neto may have additional functions at glutamatergic central synapses. As in vertebrates, neuronal Neto is not essential; only the NMJ function of Neto is required for viability. While a role for Neto at central synapses remains to be determined, it is tempting to speculate that Drosophila Netos might have attained tissue- or context-specific roles in modulation of iGluRs. Thus, Netos constitute a family of conserved proteins that influence the function of glutamatergic synapses and have acquired species- and tissue-specific roles during evolution.

\section{Materials and methods}

Fly stocks

To generate neto imprecise excisions, the Minos transposomal elements Mi(ET1)CG32635 ${ }^{\mathrm{MB05569}}$ (BL-25300) and Mi(ET1)CG32635 ${ }^{\mathrm{MB04917}}$ (BL-24730) were mobilized using the Minos transposase (BL-24613) (Bellen et al. 2011). The resulting lines were characterized by PCR amplification over the deficiencies and DNA sequencing. The genomic fragments removed in various neto alleles were as follows: neto ${ }^{36}, \mathrm{X}$ : 13391744-13394080, including exon 5 of the predicted neto gene; neto ${ }^{14}$, X: 13391517-13395954, containing exons 5 and 6; and neto $^{109}, \mathrm{X}: 13374424-13378804$, containing exon 3 . The duplication covering neto locus used in this study is $D p(1: 3) D C 270$, PBac(DC270)VK00033 (BL-30387) (Venken et al. 2010).

UAS-neto lines were generated by insertion of the neto cDNA (tagged or nontagged) in pUAST and pUASg vectors and germline transformation (BestGene, Inc.).

Other fly stocks used in this study were da-Gal4 (BL-5460), 24B-Gal4 (BL-1716), and elav-Gal4 (BL-8760). The G14-Gal4 and MHC-Gal4 were obtained from C. Goodman (University of California at Berkeley), and btl-Gal4 was obtained from Kelly Ten Hagen (NIH).

\section{Molecular constructs}

Full-length cDNA for Drosophila neto from GH11189 (EcoRI/ XhoI) was subcloned in pUAST-digested EcoRI/XhoI and used to generate nontagged neto transgenes. V5-His or eGFP tags were PCR-amplified and introduced in-frame at the C end of neto cDNA using QuikChange site-directed mutagenesis kit (Stratagene). Tagged variants were similarly subcloned in pUAST and pUASg or in pAcPA-based plasmids toward expression in S2 insect cells under the actin promoter. Further truncations were generated by looping out various Neto domains using the QuikChange site-directed mutagenesis kit. All constructs were verified by DNA sequencing.

\section{Protein analyses and antibody generation}

Drosophila S2 cells were used for producing recombinant proteins as described previously (Serpe and O'Connor 2006). 
The rat polyclonal anti-Neto antibody was generated against the CUB1 domain of the fly Neto produced in S2 cells. An AcPA-based construct containing CUB1 domain C-tagged with V5-His cassette from pIB-V5/His (Invitrogen) was transiently transfected in S2 cells, and the secreted fragment was purified from conditioned supernatant using a His-Trap column (Pharmacia). The CUB1-enriched eluate was further purified by SDS-PAGE, and a gel band was used as antigen (Open Biosystems).

To analyze muscle proteins, wandering third instar larvae were dissected, and all tissues except for the body wall (muscle and cuticle) were removed. The body walls were mechanically disrupted and lysed in lysis buffer A $(50 \mathrm{mM}$ HEPES- $\mathrm{NaOH}$ at $\mathrm{pH}$ 7.5, $150 \mathrm{mM} \mathrm{NaCl}, 0.2 \mathrm{mM}$ EDTA, 0.5\% NP-40, 0.1\% SDS, protease inhibitor cocktail [Roche]) for $30 \mathrm{~min}$ on ice. The lysates were separated by SDS-PAGE on $4 \%-12 \%$ NuPAGE gels (Invitrogen) and transferred onto PVDF membranes (Millipore). For coimmunoprecipitation, larvae were hand-homogenized in lysis buffer B $(50 \mathrm{mM}$ HEPES- $\mathrm{NaOH}$ at $\mathrm{pH} 7.5,150 \mathrm{mM} \mathrm{NaCl}$, $0.5 \%$ Nonidet P-40, $0.1 \%$ SDS, 2 mM AEBSF [MP BIO], protease inhibitor cocktail [Roche]), extracted for $20 \mathrm{~min}$ on ice, and centrifuged at $13,000 \mathrm{rpm}$ for $30 \mathrm{~min}$ at $4^{\circ} \mathrm{C}$. The supernatants were incubated with anti-V5 agarose bead slurry (Bethyl Laboratories) overnight at $4^{\circ} \mathrm{C}$, washed with buffer $\mathrm{B}$, and analyzed by Western. Primary antibodies were used at the following dilutions: anti-Neto, 1:1000; anti-GFP (Abcam), 1:2000; anti-GluRIIB, 1:2000; anti-Dlg (4F3), 1:1000; anti-tubulin (Sigma), 1:1000. Immune complexes were visualized using secondary antibodies coupled with IR-Dye 700 or IR-Dye 800 followed by scanning with the Odyssey infrared imaging system (Li-cor Biosciences).

\section{Immunohistology}

Wandering third instar larvae were dissected as described previously in ice-cooled $\mathrm{Ca}^{2+}$-free HL-3 solution (Stewart et al. 1994; Budnik et al. 2006). Embryos 18 h AEL were dechorionated and genotyped and, after an additional incubation $(2 \mathrm{~h}$ at room temperature), were dissected as described previously (Budnik et al. 2006). The samples were fixed in either $4 \%$ formaldehyde or Bouin's fixative (Polysciences, Inc.) and blocked by incubation with $5 \%$ normal goat serum in PBS containing $0.2 \%$ Tween-20. For detergent-free staining, we used PBS for blocking and incubation with primary antibodies. Primary antibodies from Developmental Studies Hybridoma Bank were used at the following dilutions: mouse anti-GluRIIA (MH2B), 1:200; mouse anti-Dlg (4F3), 1:1000; mouse anti-Brp (Nc82), 1:200; mouse anti-CSP (6D6), 1:1000; mouse anti$\alpha$-spectrin (3A9), 1:1000; mouse anti-futsch (22C10), 1:5. Other primary antibodies were as follows: rabbit anti-GluRIIB, 1:2000 (a gift from David Featherstone) (Chen and Featherstone 2011); rabbit anti-GluRIIC, 1:2000 (a gift from Aaron DiAntonio) (Marrus et al. 2004); rabbit anti-PAK, 1:2000 (a gift from Nicholas Harden) (Conder et al. 2004); FITC-, rhodamine-, and Cy5conjugated goat anti-HRP, 1:1000 (Jackson ImmunoResearch Laboratories, Inc.); rabbit anti-GFP, 1:250 (Abcam); rat anti-Neto, 1:1000. Alexa Fluor 488-, Alexa Fluor 568-, and Alexa Fluor 647conjugated secondary antibodies (Molecular Probes) were used at 1:400. All samples were mounted with ProLong Gold reagent (Invitrogen). In each experiment, samples of different genotypes were processed simultaneously and imaged under identical confocal settings. Quantification of NMJ morphological features was performed at muscles 6/7 of abdominal segment 2, 3, 4, and 5 . Boutons were counted using the anti-HRP staining. The numbers of samples analyzed are indicated inside the bars in Supplemental Figure S6.

\section{Electron microscopy}

Wandering third instar larvae were dissected in Jan's saline containing $0.1 \mathrm{mM} \mathrm{Ca}^{2+}$ and processed according to published protocols (Ramachandran and Budnik 2010).

\section{Electrophysiology}

The standard larval body wall muscle preparation first developed by Jan and Jan (1976) was used for electrophysiological recordings (Zhang et al. 1998; Bao et al. 2005). Wandering third instar larvae were dissected in physiological saline HL-3 saline (Stewart et al. 1994), washed, and immersed in HL-3 containing $0.8 \mathrm{mM} \mathrm{Ca}^{2+}$. The nerve roots were cut near the exiting site of the ventral nerve cord so that the motor nerve could be later picked up by a suction electrode. Intracellular recordings were made from muscle 6. Data were used when the input resistance of the muscle was $>5 \mathrm{M} \Omega$ and the resting membrane potential was between $-60 \mathrm{mV}$ and $-80 \mathrm{mV}$. The input resistance of the recording microelectrode (backfilled with $3 \mathrm{M} \mathrm{KCl}$ ) ranged from 20 to $25 \mathrm{M} \Omega$. Muscle synaptic potentials were recorded using an Axon Clamp 2B amplifier (Axon Instruments) and pClamp software. Following motor nerve stimulation with a suction electrode (100 $\mu \mathrm{sec}, 5 \mathrm{~V}$ ), evoked EJPs were recorded. Three to five EJPs evoked by low frequency of stimulation $(0.1 \mathrm{~Hz})$ were averaged. For mini recordings , TTX $(1 \mu \mathrm{M})$ was added to prevent unwanted evoked release (Stewart et al. 1994). To calculate mEJP mean amplitudes, 50-100 events from each muscle were measured and averaged using the Mini Analysis program (Synaptosoft). Minis with a slow rise and falling time arising from neighboring electrically coupled muscle cells were excluded from analysis (Gho 1994; Zhang et al. 1998). In addition, when comparing mini sizes between preparations, the Kolmogorov-Smirnov test was administrated. Quantal content was calculated by dividing the mean EJP by the mean mEJP after correction of EJP amplitude for nonlinear summation according to the methods described by Stevens (1976) and Feeney et al. (1998). Corrected EJP amplitude $=\mathrm{E}\{\operatorname{Ln}[\mathrm{E} /(\mathrm{E}-$ recorded $\mathrm{EJP})]\}$, where $\mathrm{E}$ is the difference between reversal potential and resting potential. The reversal potential used in this correction was $0 \mathrm{mV}$ (Feeney et al. 1998; Lagow et al. 2007). Data are presented as mean \pm SEM, unless otherwise specified; EJP amplitudes and quantal contents after the nonlinear correction are shown.

A one-way analysis of variance followed by Tukey's HSD test was used to assess statistically significant differences among the genotypes. Differences were considered significant at $P<0.05$.

\section{Negative geotaxis}

Female flies from wild type, neto ${ }^{109}$, and neto ${ }^{109} ;$;D were tested within $48 \mathrm{~h}$ after eclosure. Flies were placed at the bottom of a scaled cylinder of $30 \mathrm{~cm}$ total length. The fraction of flies above the $10-\mathrm{cm}$ mark after $10 \mathrm{sec}$ was recorded (climbing index). The assays were repeated three times for each genotype, and mean values were calculated.

\section{Acknowledgments}

We thank Ed Giniger, Mark Mayer, Chi-Hon Lee, Alan Hinnebusch, Kevin Cook, and Mike O'Connor for helpful discussions and suggestions. We are grateful to Aaron DiAntonio, David Featherstone, and Nicholas Harden for antibodies. We thank Peter Nguyen for technical assistance. This work was supported in part by the Intramural Research Program at NIH. H.B. and B.Z. were supported by grants from NIH/NINDS (R01NS06878) and NSF (IOS0822236 and IOS-1025556). 


\section{References}

Aberle H, Haghighi AP, Fetter RD, McCabe BD, Magalhaes TR, Goodman CS. 2002. Wishful thinking encodes a BMP type II receptor that regulates synaptic growth in Drosophila. Neuron 33: 545-558.

Ahmari SE, Buchanan J, Smith SJ. 2000. Assembly of presynaptic active zones from cytoplasmic transport packets. Nat Neurosci 3: 445-451.

Akins MR, Biederer T. 2006. Cell-cell interactions in synaptogenesis. Curr Opin Neurobiol 16: 83-89.

Anderson MJ, Cohen MW. 1977. Nerve-induced and spontaneous redistribution of acetylcholine receptors on cultured muscle cells. J Physiol 268: 757-773.

Bao H, Daniels RW, MacLeod GT, Charlton MP, Atwood HL, Zhang B. 2005. AP180 maintains the distribution of synaptic and vesicle proteins in the nerve terminal and indirectly regulates the efficacy of $\mathrm{Ca}^{2+}$-triggered exocytosis. I Neurophysiol 94: 1888-1903.

Bellen HJ, Levis RW, He Y, Carlson JW, Evans-Holm M, Bae E, Kim J, Metaxakis A, Savakis C, Schulze KL, et al. 2011. The Drosophila gene disruption project: Progress using transposons with distinctive site specificities. Genetics 188: 731-743.

Bogdanik L, Framery B, Frölich A, Franco B, Mornet D, Bockaert J, Sigrist SJ, Grau Y, Parmentier ML. 2008. Muscle dystroglycan organizes the postsynapse and regulates presynaptic neurotransmitter release at the Drosophila neuromuscular junction. PLOS ONE 3: e2084. doi: 10.1371/journal.pone.0002084.

Bresler T, Shapira M, Boeckers T, Dresbach T, Futter M, Garner CC, Rosenblum K, Gundelfinger ED, Ziv NE. 2004. Postsynaptic density assembly is fundamentally different from presynaptic active zone assembly. I Neurosci 24: 1507-1520.

Broadie KS. 1999. Development of electrical properties and synaptic transmission at the embryonic neuromuscular junction. Int Rev Neurobiol 43: 45-67.

Broadie K, Bate M. 1993a. Activity-dependent development of the neuromuscular synapse during Drosophila embryogenesis. Neuron 11: 607-619.

Broadie K, Bate M. 1993b. Innervation directs receptor synthesis and localization in Drosophila embryo synaptogenesis. $\mathrm{Na}$ ture 361: 350-353.

Budnik V, Gorczyca M, Prokop A. 2006. Selected methods for the anatomical study of Drosophila embryonic and larval neuromuscular junctions. Int Rev Neurobiol 75: 323-365.

Chen K, Featherstone DE. 2005. Discs-large (DLG) is clustered by presynaptic innervation and regulates postsynaptic glutamate receptor subunit composition in Drosophila. BMC Biol 3: 1. doi: 10.1186/1741-7007-3-1.

Chen K, Featherstone DE. 2011. Pre and postsynaptic roles for Drosophila CASK. Mol Cell Neurosci 48: 171-182.

Chen K, Merino C, Sigrist SJ, Featherstone DE. 2005. The 4.1 protein coracle mediates subunit-selective anchoring of Drosophila glutamate receptors to the postsynaptic actin cytoskeleton. J Neurosci 25: 6667-6675.

Conder R, Yu H, Ricos M, Hing H, Chia W, Lim L, Harden N. 2004. dPak is required for integrity of the leading edge cytoskeleton during Drosophila dorsal closure but does not signal through the JNK cascade. Dev Biol 276: 378-390.

Copits BA, Robbins JS, Frausto S, Swanson GT. 2011. Synaptic targeting and functional modulation of GluK1 kainate receptors by the auxiliary neuropilin and tolloid-like (NETO) proteins. I Neurosci 31: 7334-7340.

DiAntonio A. 2006. Glutamate receptors at the Drosophila neuromuscular junction. Int Rev Neurobiol 75: 165-179.

DiAntonio A, Petersen SA, Heckmann M, Goodman CS. 1999. Glutamate receptor expression regulates quantal size and quantal content at the Drosophila neuromuscular junction. J Neurosci 19: 3023-3032.

Featherstone DE, Davis WS, Dubreuil RR, Broadie K. 2001. Drosophila $\alpha$ - and $\beta$-spectrin mutations disrupt presynaptic neurotransmitter release. J Neurosci 21: 4215-4224.

Featherstone DE, Rushton E, Rohrbough J, Liebl F, Karr J, Sheng Q, Rodesch CK, Broadie K. 2005. An essential Drosophila glutamate receptor subunit that functions in both central neuropil and neuromuscular junction. J Neurosci 25: 3199-3208.

Feeney CJ, Karunanithi S, Pearce J, Govind CK, Atwood HL. 1998. Motor nerve terminals on abdominal muscles in larval flesh flies, Sarcophaga bullata: Comparisons with Drosophila. J Comp Neurol 402: 197-209.

Gally C, Eimer S, Richmond JE, Bessereau JL. 2004. A transmembrane protein required for acetylcholine receptor clustering in Caenorhabditis elegans. Nature 431: 578-582.

Gho M. 1994. Voltage-clamp analysis of gap junctions between embryonic muscles in Drosophila. J Physiol 481: 371-383.

Groc L, Choquet D. 2006. AMPA and NMDA glutamate receptor trafficking: Multiple roads for reaching and leaving the synapse. Cell Tissue Res 326: 423-438.

Hansen KB, Furukawa H, Traynelis SF. 2010. Control of assembly and function of glutamate receptors by the aminoterminal domain. Mol Pharmacol 78: 535-549.

Jackson AC, Nicoll RA. 2011. The expanding social network of ionotropic glutamate receptors: TARPs and other transmembrane auxiliary subunits. Neuron 70: 178-199.

Jan LY, Jan YN. 1976. Properties of the larval neuromuscular junction in Drosophila melanogaster. J Physiol 262: 189-214.

Kalashnikova E, Lorca RA, Kaur I, Barisone GA, Li B, Ishimaru T, Trimmer IS, Mohapatra DP, Diaz E. 2010. SynDIG1: An activity-regulated, AMPA- receptor-interacting transmembrane protein that regulates excitatory synapse development. Neuron 65: 80-93.

Keshishian H, Chiba A, Chang TN, Halfon MS, Harkins EW, Jarecki J, Wang L, Anderson M, Cash S, Halpern ME, et al. 1993. Cellular mechanisms governing synaptic development in Drosophila melanogaster. J Neurobiol 24: 757-787.

Kim E, Sheng M. 2004. PDZ domain proteins of synapses. Nat Rev Neurosci 5: 771-781.

Kumar J, Schuck P, Mayer ML. 2011. Structure and assembly mechanism for heteromeric kainate receptors. Neuron 71: 319-331.

Lagow RD, Bao H, Cohen EN, Daniels RW, Zuzek A, Williams WH, Macleod GT, Sutton RB, Zhang B. 2007. Modification of a hydrophobic layer by a point mutation in syntaxin $1 \mathrm{~A}$ regulates the rate of synaptic vesicle fusion. PLOS Biol 5: e72. doi: 10.1371/journal.pbio.0050072.

Lahey T, Gorczyca M, Jia XX, Budnik V. 1994. The Drosophila tumor suppressor gene $\mathrm{dlg}$ is required for normal synaptic bouton structure. Neuron 13: 823-835.

Liebl FL, Featherstone DE. 2008. Identification and investigation of Drosophila postsynaptic density homologs. Bioinform Biol Insights 2: 375-387.

Marrus SB, DiAntonio A. 2004. Preferential localization of glutamate receptors opposite sites of high presynaptic release. Curr Biol 14: 924-931.

Marrus SB, Portman SL, Allen MJ, Moffat KG, DiAntonio A. 2004. Differential localization of glutamate receptor subunits at the Drosophila neuromuscular junction. I Neurosci 24: 1406-1415.

McMahan UJ. 1990. The agrin hypothesis. Cold Spring Harb Symp Quant Biol 55: 407-418.

Milstein AD, Nicoll RA. 2008. Regulation of AMPA receptor gating and pharmacology by TARP auxiliary subunits. Trends Pharmacol Sci 29: 333-339. 
Morimoto T, Nobechi M, Komatsu A, Miyakawa H, Nose A. 2009. Subunit-specific and homeostatic regulation of glutamate receptor localization by CaMKII in Drosophila neuromuscular junctions. Neuroscience 165: 1284-1292.

Ng D, Pitcher GM, Szilard RK, Sertie A, Kanisek M, Clapcote SI, Lipina T, Kalia LV, Joo D, McKerlie C, et al. 2009. Neto1 is a novel CUB-domain NMDA receptor-interacting protein required for synaptic plasticity and learning. PLOS Biol 7: e1000041. doi: 10.1371/journal.pbio.1000041.

O'Brien RJ, Xu D, Petralia RS, Steward O, Huganir RL, Worley P. 1999. Synaptic clustering of AMPA receptors by the extracellular immediate-early gene product Narp. Neuron 23: 309-323.

Parnas D, Haghighi AP, Fetter RD, Kim SW, Goodman CS. 2001. Regulation of postsynaptic structure and protein localization by the Rho-type guanine nucleotide exchange factor dPix. Neuron 32: 415-424.

Passafaro M, Nakagawa T, Sala C, Sheng M. 2003. Induction of dendritic spines by an extracellular domain of AMPA receptor subunit GluR2. Nature 424: 677-681.

Petersen SA, Fetter RD, Noordermeer JN, Goodman CS, DiAntonio A. 1997. Genetic analysis of glutamate receptors in Drosophila reveals a retrograde signal regulating presynaptic transmitter release. Neuron 19: 1237-1248.

Pielage J, Fetter RD, Davis GW. 2005. Presynaptic spectrin is essential for synapse stabilization. Curr Biol 15: 918-928.

Qin G, Schwarz T, Kittel RJ, Schmid A, Rasse TM, Kappei D, Ponimaskin E, Heckmann M, Sigrist SJ. 2005. Four different subunits are essential for expressing the synaptic glutamate receptor at neuromuscular junctions of Drosophila. J Neurosci 25: 3209-3218.

Ramachandran P, Budnik V. 2010. Electron microscopy of Drosophila larval neuromuscular junctions. Cold Spring Harb Protoc 8: pdb.prot5474. doi: 10.1101/pdb.prot5474.

Rasse TM, Fouquet W, Schmid A, Kittel RJ, Mertel S, Sigrist CB, Schmidt M, Guzman A, Merino C, Qin G, et al. 2005. Glutamate receptor dynamics organizing synapse formation in vivo. Nat Neurosci 8: 898-905.

Regus-Leidig H, Tom Dieck S, Specht D, Meyer L, Brandstatter JH. 2009. Early steps in the assembly of photoreceptor ribbon synapses in the mouse retina: The involvement of precursor spheres. J Comp Neurol 512: 814-824.

Rohrbough J, Rushton E, Woodruff E III, Fergestad T, Vigneswaran K, Broadie K. 2007. Presynaptic establishment of the synaptic cleft extracellular matrix is required for post-synaptic differentiation. Genes \& Dev 21: 2607-2628.

Saglietti L, Dequidt C, Kamieniarz K, Rousset MC, Valnegri P, Thoumine O, Beretta F, Fagni L, Choquet D, Sala C, et al. 2007. Extracellular interactions between GluR2 and N-cadherin in spine regulation. Neuron 54: 461-477.

Sanes JR, Lichtman JW. 2001. Induction, assembly, maturation and maintenance of a postsynaptic apparatus. Nat Rev Neurosci 2: 791-805.

Schmid A, Qin G, Wichmann C, Kittel RJ, Mertel S, Fouquet W, Schmidt M, Heckmann M, Sigrist SJ. 2006. Non-NMDAtype glutamate receptors are essential for maturation but not for initial assembly of synapses at Drosophila neuromuscular junctions. I Neurosci 26: 11267-11277.

Schulze KL, Broadie K, Perin MS, Bellen HJ. 1995. Genetic and electrophysiological studies of Drosophila syntaxin-1A demonstrate its role in nonneuronal secretion and neurotransmission. Cell 80: 311-320.

Schwabe T, Bainton RJ, Fetter RD, Heberlein U, Gaul U. 2005. GPCR signaling is required for blood-brain barrier formation in Drosophila. Cell 123: 133-144.

Schwenk J, Harmel N, Zolles G, Bildl W, Kulik A, Heimrich B, Chisaka O, Jonas P, Schulte U, Fakler B, et al. 2009.
Functional proteomics identify cornichon proteins as auxiliary subunits of AMPA receptors. Science 323: 1313-1319.

Serpe M, O'Connor MB. 2006. The metalloprotease tolloidrelated and its TGF- $\beta$-like substrate Dawdle regulate Drosophila motoneuron axon guidance. Development 133: 4969-4979.

Shepherd JD, Huganir RL. 2007. The cell biology of synaptic plasticity: AMPA receptor trafficking. Annu Rev Cell Dev Biol 23: 613-643.

Sia GM, Beique JC, Rumbaugh G, Cho R, Worley PF, Huganir RL. 2007. Interaction of the $\mathrm{N}$-terminal domain of the AMPA receptor GluR4 subunit with the neuronal pentraxin NP1 mediates GluR4 synaptic recruitment. Neuron 55: 87-102.

Stevens CF. 1976. A comment on Martin's relation. Biophys J 16: 891-895.

Stewart BA, Atwood HL, Renger JJ, Wang J, Wu CF. 1994. Improved stability of Drosophila larval neuromuscular preparations in haemolymph-like physiological solutions. J Comp Physiol A 175: 179-191.

Straub C, Hunt DL, Yamasaki M, Kim KS, Watanabe M, Castillo PE, Tomita S. 2011a. Distinct functions of kainate receptors in the brain are determined by the auxiliary subunit Netol. Nat Neurosci 14: 866-873.

Straub C, Zhang W, Howe JR. 2011b. Neto2 modulation of kainate receptors with different subunit compositions. J Neurosci 31: 8078-8082.

Tang M, Pelkey KA, Ng D, Ivakine E, McBain CJ, Salter MW, McInnes RR. 2011. Neto1 is an auxiliary subunit of native synaptic kainate receptors. J Neurosci 31: 10009-10018.

Tomita S, Chen L, Kawasaki Y, Petralia RS, Wenthold RJ, Nicoll RA, Bredt DS. 2003. Functional studies and distribution define a family of transmembrane AMPA receptor regulatory proteins. J Cell Biol 161: 805-816.

Venken KJ, Popodi E, Holtzman SL, Schulze KL, Park S, Carlson JW, Hoskins RA, Bellen HJ, Kaufman TC. 2010. A molecularly defined duplication set for the $\mathrm{X}$ chromosome of Drosophila melanogaster. Genetics 186: 1111-1125.

von Engelhardt J, Mack V, Sprengel R, Kavenstock N, Li KW, Stern-Bach Y, Smit AB, Seeburg PH, Monyer H. 2010. CKAMP44: A brain-specific protein attenuating short-term synaptic plasticity in the dentate gyrus. Science 327: 1518-1522.

Wagh DA, Rasse TM, Asan E, Hofbauer A, Schwenkert I, Durrbeck H, Buchner S, Dabauvalle MC, Schmidt M, Qin G, et al. 2006. Bruchpilot, a protein with homology to ELKS/ CAST, is required for structural integrity and function of synaptic active zones in Drosophila. Neuron 49: 833-844.

Walker CS, Francis MM, Brockie PJ, Madsen DM, Zheng Y, Maricq AV. 2006. Conserved SOL-1 proteins regulate ionotropic glutamate receptor desensitization. Proc Natl Acad Sci 103: 10787-10792.

Wu H, Xiong WC, Mei L. 2010. To build a synapse: Signaling pathways in neuromuscular junction assembly. Development 137: 1017-1033.

Zhang B, Koh YH, Beckstead RB, Budnik V, Ganetzky B, Bellen HJ. 1998. Synaptic vesicle size and number are regulated by a clathrin adaptor protein required for endocytosis. Neuron 21: $1465-1475$.

Zhang W, St-Gelais F, Grabner CP, Trinidad JC, Sumioka A, Morimoto-Tomita M, Kim KS, Straub C, Burlingame AL, Howe JR, et al. 2009. A transmembrane accessory subunit that modulates kainate-type glutamate receptors. Neuron 61: 385-396.

Zheng Y, Mellem JE, Brockie PJ, Madsen DM, Maricq AV. 2004. SOL-1 is a CUB-domain protein required for GLR-1 glutamate receptor function in C. elegans. Nature 427: 451-457. 


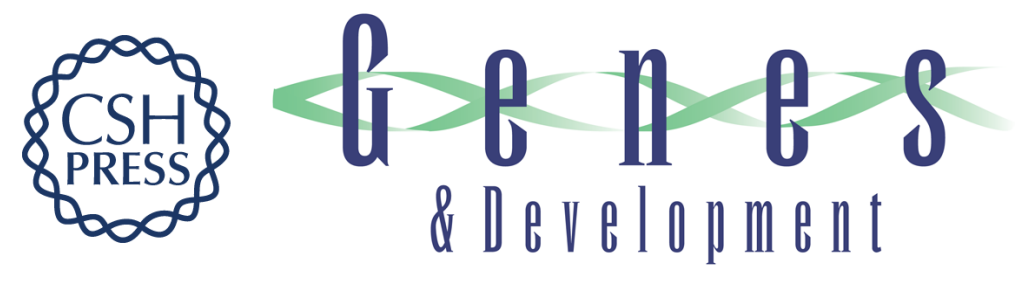

\section{Drosophila Neto is essential for clustering glutamate receptors at the neuromuscular junction}

Young-Jun Kim, Hong Bao, Liana Bonanno, et al.

Genes Dev. 2012, 26: originally published online April 12, 2012

Access the most recent version at doi:10.1101/gad.185165.111

\section{Supplemental http://genesdev.cshlp.org/content/suppl/2012/04/05/gad.185165.111.DC1 Material}

References This article cites 74 articles, 20 of which can be accessed free at: http://genesdev.cshlp.org/content/26/9/974.full.html\#ref-list-1

\section{License}

Email Alerting

Service

Receive free email alerts when new articles cite this article - sign up in the box at the top right corner of the article or click here.

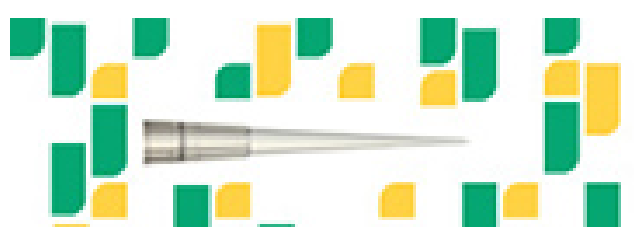

Focused on your science. 